\title{
Using Financial Ratios and Managing Financial Risks in Investing in "Grey" Zone Companies: Evidence from Malaysia
}

\author{
Ben Chin-Fook Yap (Corresponding Author) \\ UniversitiTun Abdul Razak, Capital Square, Block C \& D \\ No. 8, Jalan MunshiAbdullah, 50100 Kuala Lumpur, Malaysia \\ Tel: 60377277126 E-mail: benyap@unirazak.edu.my \\ Gary James Clayton \\ UniversitiTun Abdul Razak \\ UniversitiTun Abdul Razak, Capital Square, Block C \& D \\ No. 8, Jalan MunshiAbdullah, 50100 Kuala Lumpur, Malaysia \\ Tel: 60377277121 E-mail: gclayton@unirazak.edu.my \\ Zulkifflee Bin Mohamed \\ UniversitiTun Abdul Razak \\ UniversitiTun Abdul Razak, Capital Square, Block C \& D \\ No. 8, Jalan MunshiAbdullah, 50100 Kuala Lumpur, Malaysia \\ Tel: 60377277129 E-mail:zulkifflee@unirazak.edu.my
}

Received: 22-07- 2013

doi:10.7575/aiac.ijfas.v.1n.2p.1

URL: http://dx.doi.org/10.7575/aiac.ijfas.v.1n.2p.1

\begin{abstract}
Most studies on company financial performance have mainly focused on either the successful companies or companies that are already in financial distress. However, there is a large group of companies that are in between, that is they are average performers and can be described as belonging to the "grey" zone. The purpose of this study is to analyze the companies in the "grey" zone to identify those that are likely to go into financial distress over time and those that may progress into the good financial performing category. Utilizing 3 key financial ratios, 90 Malaysian publicly listed companies in the manufacturing sector were initially classified into 3 clusters using" Cluster Analysis" over the period 2006-2010. The classification accuracy in each year is then tested by applying Multiple Discriminant Analysis (MDA). Interestingly, a classification accuracy of more than $90 \%$ was obtained for each of the 5 years. The companies in the "grey" zone in the years 2006 and 2010 were further cluster analysed into the below average and into the above average clusters. Out of the 63 companies that were found to be in the "grey" zone in the 2 years under review, 31 companies or $50 \%$ improved their position, 18 companies or $28 \%$ declined with 14 companies or $22 \%$ remaining stagnant. Of special interest would be 5 companies that moved up 3 clusters from poor to good performers and 21 companies that moved up 2 clusters from poor to above average performers. Of concern would be 17 companies that move down one cluster and 1 company dramatically collapsing two clusters downward. A key finding of the study is that by appropriately utilizing financial ratios, investor risk can be minimized. In addition it enhances credit evaluation, stock market value and investment potential.
\end{abstract}

Keywords: Financial Risk Management, Financial Strategy, Financial Ratios, company financial performance, cluster analysis and multiple discriminant analysis.

\section{Introduction}

Company financial performance is links strategy with its operations monetarily. It is about both the effective and efficient use of deployed resources and utilized assets to generate revenue, manage its costs, produce profit and add value to its stakeholders. Put most simply, financial performance is the process of evaluating the monetary results of a firm's ongoing operations. While measured in monetary terms the performance of a company depends on a variety of factors including the economic conditions, the products and services the company has to offer, it's financial strength together with the quality of its management team and the ability of its leader.

Generally companies face financial difficulties when there is a marked downturn in the economy, consecutive years of low profitability, losses, a decline in the industry the company operates in, poor management and weak leadership. The last two being overall the most important as highlighted by Whitaker (1999) in his study on the early stages of financial distress which concluded that companies are more likely to enter into financial distress due to poor management than overall economic conditions. Whitaker reinforced the importance of good management when he noted that while improvement in industry economic conditions was a significant determinant of recovery from an economic distress this did not appear true for companies that were poorly managed. 
While organizations can use a variety of measures to assess the financial performance and health of an organization they can be divided into two generic types, Financial and non-Financial measures (Khandwalla, 1972). Financial measures involve the use of accounting and other numerical data such as ratios and trends to measure a company's growth, profitability, efficient use of its assets and its financial standing at different points in time. The inclusion of items that can only be measured in monetary terms tend to over emphasize savings and cost reductions at the expense of other equally important variables such as product quality and customer satisfaction (Anderson \& Young, 1999; Chenhall, 2003). Furthermore, quantitative measures alone are unable to adequately measure the 'quality' of the management team.

In order to account for the importance of qualitative variables to company performance, tools such as "The Tableau de Bord" (Daum, 2005) and "The Balance Scorecard" (Kaplan \& Norton, 1996) have been developed. These tools look to measure both qualitative and quantitative variables simultaneously to assess the overall strategic performance of the organization (Divandri \&Yousefi, 2011). Such tools are critical to success as highlighted by Watkins (2003) study of non-financial measures to assess financial performance, in which she suggested that non-financial measures might be more telling than traditional financial measures including output, efficiency and productivity. In a five year longitudinal study she identified seven variables, three of which were non-Financial that when routinely measured enhanced the financial analysis of an organization.

Despite the research findings on the importance of non-Financial measures the more traditional and popularly used financial measures still dominate with respect to assessing corporate health (BCOBS, 2011). This is largely due to the fact that most businesses and corporations are obliged to produce a set of financial statements annually or at more frequent intervals to comply with legal and regulatory requirements. However, analyzing and evaluating a company's financial performance and financial position is rarely easy. Unless trained in at least the basics of accounting and finance the amount of data contained in a set of financial statements can be overwhelming and intimidating to investors and other potential stakeholders of the company. Yet when it comes to understanding how a company has performed and its future performance prospects, analyzing financial statements is one of the most important aspect of the fundamental analysis process. Using financial ratios to analyze and explain figures in the financial statements in a systematic and timely manner is a common but a very valuable tool in a manager or an analyst's bag of tools used to obtained informed opinions about a company's profitability, liquidity, asset utilization efficiency and indebtedness. Financial statement analysis looks at a firm's past performance to predict its future condition (Eidleman, 1995).

In addition to assisting stakeholders with a gauge of performance, financial analysis provides researchers with the capacity to classify and compare companies. Generally classification is either into failed and non-failed or bankrupt and successful (Beaver 1966, Altman 1968, Ohlson1990, Inman 1991 and Ganelasingam \& Kumar, 2001, Gepp \& Kumar 2008 and Muller et al. 2009). The surveyed companies in these studies have been financially stable, in financial distress or have actually collapsed. What has been overlooked is the larger group of companies that are "average", where they fall into the "grey cluster" or "grey zone". Companies in the "grey zone" normally manage to achieve a reasonable return on its assets or equity and show an acceptable financial position at the end of each year. These companies can either progressed into the ranks of good performing companies or decline to become poor performers where their chances of slipping into failure and bankruptcy are much higher given the volatile economic and market conditions the world is facing over the last few years since the onset of the financial crisis in 2008.

The purpose of this study is to examine and classify the financial performance of 90 manufacturing companies listed in the Bursa Saham Malaysia (formerly known as the Kuala Lumpur Stock Exchange) using both "Cluster Analysis" and "Multiple Discriminant Analysis" techniques. The study is a five year longitudinal review from 2006-2010. It first uses "Cluster Analysis" to classify the sample group into three clusters good, average and poor performers. "Multiple Discriminant Analysis" was then used for the same sample group to check the accuracy of the "Cluster Analysis" results.

In addition, the companies in the "grey zone" for 2006 and 2010 were re-analyzed using the same set of financial ratios to reclassify them into above average and below average financial performers. Each of these companies were then examined to see how they have performed over the five years and determined whether they have moved or migrated from one category to another. Analysts, lending institutions and other stakeholders will be able to obtain a better understanding of companies other than those that are either very successful or are already in financial distress. Potential investors and fund managers may find investing opportunities in some of these companies and at the same time be aware of the vulnerabilities of those other companies that do not seem to be able to move out from the below average performing category.

\section{Brief Review of Financial Ratios and Analytical Tools and Techniques.}

It is generally accepted that in the study and analysis of company performance, financial ratios whether individually or in groups provide key benchmark measures. In addition they assist in providing critical financial information about business operations including identifying and highlighting problematic areas as well as strengths in a company. For example, Chen \& Shimerda (1981) found that financial ratios have played an important part in evaluating the financial conditions of business entities and that over the years, empirical studies have repeatedly demonstrated the usefulness of financial ratios. They analyzed 26 studies done on failure prediction, market returns, bond ratings and mergers that used more than 100 financial items out of which 65 are accounting ratios. In a later study, Hossare and Rahman (2005) identified 48 ratios and ranked them according to their usefulness as portrayed in 53 studies carried out between 1966 
and 2002. Their study showed that of the top 10 most popular ratios, four each measure profitability and liquidity while two ratios measure solvency.

Due to the large number of ratios available, it is necessarily to identify a smaller set of ratios that can still meet the objectives of the study regardless of whether the ratios are used for prediction of bankruptcy, loan defaults, ratings of bonds and equity or financial performance. Karels and Prakash (1987) suggested a careful selection of ratios to be used in the development of a bankruptcy prediction model, as the choice of ratios can affect the effectiveness of the model. Koh and Killough (1986) found that it is not needed to have a large number of ratios to predict business failures and all that is needed is a set of dominant ratios derived from a larger set of related ratios. Taffler's (1983) study started with eighty potentially useful ratios and ended up with just four.

In using financial ratios to evaluate the financial performance of companies, various statistical analysis tools and techniques, both parametric and non-parametric, can be utilized. The earliest studies on company financial performances including failures and company bankruptcies were univariate in nature. The most well-known univariate model is probably the 1966 study by Beaver, which from then on, had started many other company performance and failure prediction analyses using other statistical techniques such as the multiple discriminant analysis by Altman (1968), Mutchler (1985) and Koh and Killough (1990), logistic regression method by Ohlson (1980) and Zavgren and Friedman (1998), artificially Intelligent Systems (such as artificial neural networks or ANNs) by Balcaen and Ooghe (2006) and Pramodh and Ravi (2007). Numerous studies on company performance efficiency using data envelopment analysis has also been published including those by Charnes, Cooper and Rhodes (1978), Seiford and Thrall (1990), Devinney et al. (2010) and Gumus and Cellikol (2011).

Though there are a plethora of studies utilizing a variety of ratios, few use "Cluster Analysis" to classify companies according to their financial performance. According to Sharma and Wadhawan (2009), in their study on using "Cluster Analysis" on small medium enterprises, clustering is explained as a mathematical method for segregating the observed data into groups so as to maximize the similarity of observations within the same group and minimize the similarity of observations across different groups. They used eleven variables and produced three clusters. The objective of their study is to cluster the successful SMEs based on their growth, mode and strategies. Most of the variables are non financial in nature including age of companies, changes in management principles and practices, growth orientation and characteristics of the entrepreneurs.

Jensen (1976), in a pioneering "Cluster Analysis" study of the financial performance of business firms, said that "Cluster Analysis" is about "classifying the entities into various clusters where items "within" a cluster are deemed to be more homogeneous than items "between" clusters." His study used the clustering algorithm that is based on a hierarchical method in which pairs of entities (or clusters) are sequentially merged into clusters. He made a distinction between "Cluster Analysis" and discriminant analysis as both attempt to segregated entities into homogeneous groups. In discriminant analysis, the entities are known in advance and he gave the example of a study on a sample of students who achieved a college degree as against another sample of students in the same college who did not. Discriminant analysis aims to find discernible differences between these two groups on the basis of some measurable characteristics such as high school grade averages, entrance examination scores, age etc. Therefore, the groups are already segregated based on these characteristics. The results obtained from the discriminant analysis can then be used to identify a future group of college applicants who would achieve the college degree. In cluster analysis the characteristics of the population are not known in advance and this method has to search for some factors internal or natural to the population in order to group them into groups with similar characteristics.

In addition to the hierarchical method, the other method cluster analysis is partitioning clustering. Hierarchical clusters find successive clusters using previously established clusters while partitioning clustering find all the clusters at once. Gower (1967) said that there are many techniques of cluster analysis and to judge whether one is better than another is difficult because a cluster is not a well defined concept. According to him, most methods of cluster analysis work on the basis of a multivariate sample of $\mathrm{N}$ individuals with $\mathrm{v}$ variates as observations for each individual. Zulfigar et al. (2001) in their study used the K-means cluster analysis method. This is a data mining method where $\mathrm{n}$ observations are partitioned in k clusters, where each observation belongs to the cluster with the nearest mean. The objective of their study was to find a relationship between ownership of companies and company performance. They used five variables four of which were financial ratios.

"Multiple Discriminant Analysis" in contrast to "Cluster Analysis" is basically a multivariate technique using several discrete variables simultaneously to classify an observation into one of several a priori (formal) groups. This is done by the statistical decision rule of maximizing the between group variance relative to the within-group variance and is expressed as the ratio of the between group to the within-group variance. Altman (1968), in his study of corporate bankruptcy, developed a model using "Multiple Discriminant Analysis" to determine the predictive value of financial ratios. Described as "pioneering", "seminal" and easy to use, it is now widely used internationally (Isa et al, 2005). "Multiple Discriminant Analysis" was used by Sinkey (1973), for example, to identify and describe the characteristics of problem banks and non-problem banks while Koh and Killough (1990) used it in their study on the going concern issue that auditors face. 


\section{Methodology}

\subsection{Selection of Variables and Sample.}

Three financial ratios were selected as variables for both the "Cluster Analysis" and "Multiple Discriminant Analysis". The ratios selected were:

(i) Cash flows from Operations over Total Debts (CFTD),

(ii) Earnings before Interests and Taxation over Total Assets (EBITTA) and

(iii) Total Debts over Total Assets (TDTA).

The three ratios were selected to measure liquidity, profitability and solvency respectively. They were selected due to their popularity and frequent usage in company performance evaluations. The three ratios are also ranked in the top six most frequently used ratios out of a total of 48 ratios as ranked by Hossari and Rahman (2005).

For the study 90 out of a possible 140 companies in the manufacturing industry producing consumer products as listed on the Bursa Saham Malaysia were selected at random. Their annual revenue earned and total assets values ranged from USD50 million to over USD600 million. Their audited Income Statements, Balance Sheets and Cash Flow Statements are analyzed over a period of five years from 2006 and 2010.

\subsection{Cluster Analysis}

The cluster analysis method from SPSS will be performed for each of the five years using 3 financial ratios as variables where the companies are classified or clustered into good financial performers, average and poor performers. Each cluster depending on the characteristics of the data used will defined the class they belong to. For this study, the Kmeans cluster method will be used. The K-means algorithm method is a partitioning clustering approach as opposed to the hierarchical method.

In the K-means analysis, the number of clusters ( $\mathrm{k}$ clusters) is initially specified. Each cluster will have a centroid to be called the $\mathrm{k}$ centroid. The characteristics of a cluster are the centroid or average values of the characteristic of the variables comprising the cluster. These centroids should be placed as far away as possible from each other as the location can affect the result. The next step is to take each observation and place it to the nearest centroid until no observation is left which means an early cluster is obtained. The center or centroid is the average of all the points in the cluster. It is typically the mean of all the points in that cluster. The same process is done for all the other observations and associate them with the nearest new k centroid. Re-computation is then done for each of the new clusters obtained and the process is repeated until there is some convergence or as the $\mathrm{k}$ centrods change their location step by step until no more changes take place and the centroids do not shift anymore. The K-means algorithm aims at minimizing an objective function, in this case a squared error function. The objective function is:

$$
J=\sum_{j=1}^{k} \sum_{i=1}^{n}\left\|x_{i}^{(j)}-c_{j}\right\|^{2} \int
$$

where $\left\|^{-\imath} \quad-\jmath\right\|$ is a chosen distance measure between a data point ${ }^{\Lambda_{i}}$ and the cluster centre ${ }^{\nu_{j}}$, is an indicator of the distance of the $n$ data points from their respective cluster centers. The ANOVA table will be analyzed to check on the suitability of entering the three variables into the analysis. The F statistic and significance level of each variable will be examined on the significant differences across the three clusters

\subsection{Multiple Discriminant Analysis}

The same three financial ratios will be used as the independent variables in "Multiple Discriminant Analysis" to discriminate the companies which were earlier clustered into three classifications of good, average and poor performers to further validate the accuracy of the clustering as obtained through "Cluster Analysis". The "Multiple Discriminant Analysis" function will be assessed for statistical significance. If a strong function is constructed, the groups can be classified based on the independent or predictor variables. To assess the relative importance of each of the independent variables in building the discriminant function, the discriminant weights and the discriminant loadings are analyzed. The relative contribution of each variable to the function will depends on the size and magnitude of the discriminant weights or discriminant coefficients. The larger the standardized coefficient, the larger is the variable's contribution to the function. The discriminant loadings measure the simple linear correlation between each independent variable and the discriminant function and reflect the variance shared by the independent variables and the discriminant function. The discriminant loadings in discriminant analysis are similarly interpreted as for factor loadings when the objective is to assess the relative contribution of each independent variable to the discriminant function. Partial $\mathrm{F}$ values are used when the stepwise method is utilized. The partial $\mathrm{F}$ values reflect the relative contribution of each independent variable to the discriminant function. Larger $\mathrm{F}$ values indicate greater discriminating power. However, for this study, the enter method is employed where the three independent variables are entered simultaneously and similarly employed for each of the five years.

The strength of the "Multiple Discriminant Analysis" function or the strength of its discriminating power can be evaluated by investigating the eigenvalues, the Wilk's Lambda and Chi-Square values. The larger the eigenvalues, the better the discriminating power of the function. The Wilk's Lambda is used to measure the differences between groups and the homogeneity within groups. A low Wilk's Lambda and a large Chi-Square with a significant p-value will indicate good discriminating power of the discriminant function. The Wilk's Lambda used is the ANOVA (F) test of mean differences. The Lambda values range from 0 to 1 . A value of 0 means that the group means differ and a value of 
1 means that all group means are the same. The $\mathrm{F}$ test in the Wilk's Lambda will show which of the independent variables display good discriminating power. The Box M test will be used to evaluate for the equality of the covariance matrices.

The between-group differences and within-group differences are computed as:

$$
\begin{array}{ll} 
& S S_{\text {total }} S S_{b g+}=S S_{w g} \\
\text { Where: } \quad & \mathrm{SS} \text { is the sum of squares, } \\
& w g \text { is within group and } \\
& b g \text { is between groups }
\end{array}
$$

and the equation for the test statistics Wilk's Lambda is derived as:

$$
\Lambda=S_{w g /}\left(S_{b g+} S_{w g}\right)
$$

The F statistic is calculated as:

Where:

$$
S_{\text {appromimate }}\left(S_{b g+} S_{w g)}=\left(\frac{1-y}{y}\right)\left(\frac{d f_{2}}{d f_{1}}\right)\right.
$$

\subsection{Sample}

$$
\begin{gathered}
\mathrm{y}=\Lambda^{1 / 2} \mathrm{p}=\# \text { of predictors variables } \\
s=\frac{\sqrt{p^{2}\left(\mathrm{df}_{\text {effect }}\right)^{2}-4}}{\mathrm{p}^{2}+\left(\mathrm{df}_{\text {effect }}\right)^{2}-5} \\
d f_{1=p\left(\mathrm{df}_{\text {effect }}\right)}=\text { number of groups times }(\mathrm{n}-1): \mathrm{k}(\mathrm{n}-1) \\
d f_{2}=s\left[\left(d f_{\text {error }}\right)-\frac{\mathrm{p}-d f_{\text {effect }}+1}{2}\right]-\left[\frac{p\left(d f_{\text {effect }}\right)-2}{2}\right] \\
d f_{\text {effect }}=\text { number of groups }- \text { one }(k-1)
\end{gathered}
$$

90 Malaysian publicly listed companies manufacturing consumer products were randomly selected out of a total of 140 companies as listed under the consumer sector in Bursa Saham Malaysia (formerly known as the Kuala Lumpur Stock Exchange) were initially classified into 3 clusters using "Cluster Analysis" over the period 2006-2010.

Companies clustered as average financial performers in 2006 and 2010 are further clustered into the below average and above average clusters. The movements or migrations of these companies in 2006 and in 2010 are then examined to see how they have performed over the 5 years period.

\section{Findings and Discussion}

The results after running the SPSS K-Means "Cluster Analysis" are as shown in the table below:

Table 1. Number and Percentage of Companies in the 3 Clusters

\begin{tabular}{lccccc}
\hline $\begin{array}{l}\text { No. of } \\
\text { companies }\end{array}$ & $\begin{array}{c}\text { Yr. end } \\
\mathbf{2 0 1 0}\end{array}$ & $\begin{array}{c}\text { Yr. end } \\
\mathbf{2 0 0 9}\end{array}$ & $\begin{array}{c}\text { Yr. end } \\
\mathbf{2 0 0 8}\end{array}$ & $\begin{array}{c}\text { Yr. end } \\
\mathbf{2 0 0 7}\end{array}$ & $\begin{array}{c}\text { Yr. end } \\
\mathbf{2 0 0 6}\end{array}$ \\
\hline Poor & 5 & 29 & 39 & 10 & 43 \\
Average & 60 & 58 & 35 & 40 & 36 \\
Good & 25 & 3 & 16 & 40 & 11 \\
Total & 90 & 90 & 90 & 90 & 90 \\
& & & & & \\
Percentage & & $32 \%$ & $43 \%$ & $12 \%$ & $48 \%$ \\
Poor & $6 \%$ & $\mathbf{6 5 \%}$ & $\mathbf{3 9 \%}$ & $\mathbf{4 4 \%}$ & $\mathbf{4 0 \%}$ \\
Average & $\mathbf{6 7 \%}$ & $3 \%$ & $18 \%$ & $44 \%$ & $12 \%$ \\
Good & $27 \%$ & $\mathbf{1 0 0 \%}$ & $\mathbf{1 0 0 \%}$ & $\mathbf{1 0 0 \%}$ & $\mathbf{1 0 0 \%}$ \\
Total & $\mathbf{1 0 0 \%}$ & & & & \\
\hline
\end{tabular}

The analysis showed that out of the 90 companies evaluated over the 5 years period from 2006 to 2010 , the number of average performing companies (in the grey zone) range from $40 \%$ to $67 \%$ which also illustrates the effect of the 2008 financial crisis that was started with the Lehman Brothers collapse. For the three years, 2008, 2009 and 2010 the number of companies that are clustered as average rose significantly due in large part to the slowdown in exports to the United States and Europe where the largest portion of the country's exports of electrical and electronic products go to. The table also showed that there were 40 companies in the good performing cluster in 2007, the year before the financial crisis started and the number of the good performing companies dropped to 16 and 3 companies in 2008 and 2009 respectively before recovering to 25 in 2010, a period that coincided with the onset of the crisis and the start of the recovery in 2010 in the United States.

The distance between the three clusters centers are relatively large for all the five years indicating that the results from the clustering process is good. The ANOVA results showed that the p-values for all the three variables or dimensions are below 0.05 . Any p-values above the significant levels of 0.05 should be excluded from the cluster analysis. For each of the five years, the cluster centroids or cluster means are significantly different for each of the variables with 
reasonable strong $\mathrm{F}$ values for the Cash Flow to Total Debts (CFTD) variable indicating that this variable discriminates well. For the Earnings before Interest and Tax to Total Asset (EBITTA) variable, the F values in the ANOVA table showed much lower values that would indicate that this particular variable do not discriminate as well as the other two variables. The details of the $\mathrm{F}$ values are as shown in Table 2 below:

Table 2. F values for the three Financial Ratios

\begin{tabular}{llllll}
\hline F Statistics & Yr 1 & Yr 2 & Yr 3 & Yr 4 & Yr 5 \\
\hline CFTL & 121.674 & 221.147 & 91.201 & 112.475 & 124.695 \\
TDTA & 27.991 & 30.177 & 99.215 & 82.693 & 92.768 \\
EBIT & 23.443 & 9.048 & 9.681 & 6.185 & 11.844 \\
\hline
\end{tabular}

The "Multiple Discriminant Analysis" results showed remarkable accuracies in its classification abilities achieving more than $90 \%$ accuracies for each of the three clusters and for each of the five years when applied on the three clusters obtained earlier using Cluster Analysis. For each of the five years analyzed, the results gave large eigenvalues, low Wilks Lambda and large chi-square values with significant p-values, all indicating a strong MDA function with strong discriminating power. The MDA model function information is as shown in Table 3 below:

Table 3. Model Function information

\begin{tabular}{llllll}
\hline & Yr 1 & Yr 2 & Yr 3 & Yr 4 & Yr 5 \\
\hline Eigenvalues & 3.026 & 5.513 & 4.907 & 4.005 & 5.029 \\
Wilks Lambda & 0.617 & 0.136 & 0.110 & 0.130 & 0.106 \\
Chi-square & 154.04 & 171.124 & 190.142 & 175.341 & 191.278 \\
Significance & 0.000 & 0.000 & 0.000 & 0.000 & 0.000 \\
\hline
\end{tabular}

There were 36 and 60 companies in the grey clusters in 2006 and 2010 respectively as well as 3 companies found in 2006 but not in the grey cluster in 2010. These 3 companies were clustered as poor performers in 2006 and five years later in 2010 they have moved up to the good performer's category. The migrations of the 63 companies are as shown in Tables 4 below:

Table 4. Migration from 2006 to 2010 - Companies in the Grey Zone

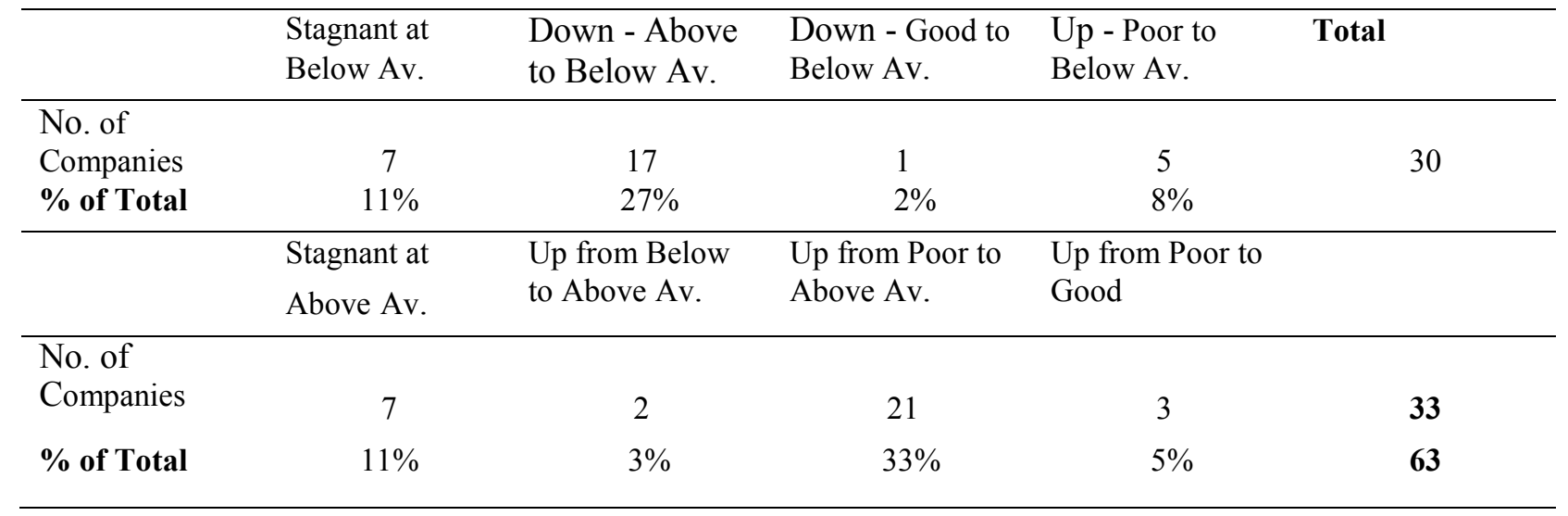

On examining the above table, 14 companies or $11 \%$ each in the below and above average cluster respectively remain stagnant and have not moved over the 5 year period. 18 companies or $28 \%$ have migrated downwards and performed not as well as before while 31 companies or $50 \%$ have migrated upwards and seems to have improved on their financial performance. Of particular interest would be 3 companies that migrated 3 clusters upwards from poor to the good cluster and the 21 companies that have migrated two clusters upwards from poor to the above average cluster. Of particular concern would be the 17 companies that migrated downwards from above average to the below average cluster and the 1 company that seems to be in financial distress having migrated 2 cluster downwards from good to the below average cluster.

\section{Limitations}

This study is limited to single market of the emerging economy of Malaysia and is further limited to the manufacturing industry producing goods for the consumer sector. To confirm and validate the findings future studies on other industry sectors and in other markets need to be undertaken. The study is also limited to using financial ratios as variables. Nonfinancial measures or a combination of both could be used in future studies. 


\section{Conclusion}

The purpose of this study is to analyze average performing companies in what can be described as belonging to the "grey" zone as opposed to either the successful or the financially distress companies, to identify those that are likely to go into financial distress over time and those that may progress into the good financial performing category. To ensure the value of any finding the study examined a relatively large group of 90 publicly listed manufacturing companies over a significant period of five years and classified them into good, average and poor performers using "Cluster Analysis". To validate the accuracy of the clusters, "Multiple Discriminant Analysis" classification matrix was utilized which highlighted a remarkable accuracy of over $90 \%$ for each of the clusters and for the whole period studied. To enhance the value of the findings, the average performing companies in the 2006 and 2010, those in the "grey" zone, were re-clustered. Using the same set of financial ratios they were reclassified into above average and below average financial performers. Each of these companies for the two years was further examined to determine their overall performance over the five year period. $28 \%$ of the companies have the possibilities of going into financial decline and distress and possible eventual failure, $50 \%$ are likely to migrate into the successful category while $22 \%$ have remained unchanged in terms of their financial performance.

The study can also be used to determine whether managers and investor's decision making could be made simpler by using a combination of "Cluster Analysis" and "Multiple Discriminant Analysis" to determine and predict the possible future migration of average performing companies. Analysts and investors will avoid companies already identified as in financial decline and possible failure. They may find that the market values of successful companies as already being too high. This study provides an alternative in that investing opportunities may be found in average performing companies where their market values are reasonable. Finally, this study highlights that with three carefully chosen financial ratios, it is possible to understand companies potential rather than simply determine whether they are either very successful or are already in financial difficulties.

\section{References}

Altman, E. I. (1968). Financial ratios, discriminant analysis and the prediction of corporate bankruptcy. Journal of Finance, 23(4), 589-609. http://dx.doi.org/10.1111/j.1540-6261.1968.tb00843.x

Balcaen, S., \& Ooghe, H. (2006). 35 Years of Studies on Business failures. An overview of the classic statistical methodologies and their related problems, The British Accounting Review, 38(1), pp. 63-93. http://dx.doi.org/10.1016/j.bar.2005.09.001

Basel Committee on Banking Supervision (BCOBS) (2011). "Range of Methodologies for Risk and Performance Alignment of Remuneration". Bank for International Settlements, Basel 2011

Beaver, W. H. (1966). Financial Ratios as Predictors of Failure, Journal of Accounting Research, 4. 71-111. http://dx.doi.org/10.2307/2490171

Charnes, A., Cooper, W., \& Rhodes, E. (1978). Measuring the efficiency of decision making units. European Journal of Operational Research, 2, 429-444. http://dx.doi.org/10.1016/0377-2217(79)90229-7

Chen, K.H., \& Shimerda, T.A. (1981). An empirical analysis of useful financial ratios. Financial Management.10(1),51-60. http://dx.doi.org/10.2307/3665113

Chenhall, R.H. 2003. Management control systems design within its organizational context:findings from contingencybased research and directions for the future. Accounting ,Organizations and Society. 28, 127-168. http://dx.doi.org/10.1016/S0361-3682(01)00027-7

Daum, J. H. (2005) "Tableau de Bord: Besserals die Balanced Scorecard? French Tableau de Bord: Better than the Balanced Scorecard? Der Controlling Berater, 7. 459-502

Divandri, A. \& Yousefi, H. (2011). "Balanced Scorecard: A Tool for Measuring Competitive Advantage of Ports with Focus on Container Terminals" International Journal of Trade, Economics and Finance, 2(6), 472-477. http://dx.doi.org/10.7763/IJTEF.2011.V2.151

Devinney, T.M., Yip, G.S., \& Johnson, G. (2010). Using Frontier Analysis to Evaluate Company Performance. British Journal of Management, 21, 921-938. http://dx.doi.org/1o.1111/j.1467-8551.2009.00650.x

Eidleman, G. J. (1995). Z scores - A guide to failure prediction, The CPA Journal, 65(2), 52-55.

Ganesalingam, S., \& Kumar, K. (2001).Detection of financial distress via multivariate statistical analysis, Managerial Finance, 27(4),45-55. http://dx.doi.org/10.1108/03074350110767132

Gepp, A., \& Kumar, K. (2008). The Role of Survival Analysis in Financial Distress Predictions, International Research Journal of Finance and Economics, 16, 13-34.

Gower, J. C. (1967). A Comparison of Some Methods of Cluster Analysis. Biometrics,23(4), 623-637. http://dx.doi.org/10.2307/2528417

Gümüs, Y., \& Celikkol, H. (2011).Data Envelopment Analysis: An Augmented Method for the Analysis of Firm Performance. International Research Journal of Finance and Economics.79, 137-142.

Inman, M. K. (1991). Z-Scores and recent events: Do they shed any light? Management Accounting, 69(1), 44-48. 
Isa H, M., Annuar, M.N., Shamsher M., \& Taufiq, H. (2005). Prediction of Corporate Financial Distress of PN4 Companies in Malaysia: A logistic Model Approach. Journal of Restructuring Finance, 2(2), 143-155.

Hossari, G., \& Rahman, S. (2005). A Comprehensive Formal Ranking of the Popularity of Financial Ratios in Multivariate Modeling of Corporate Collapse, Journal of American Academy of Business, Cambridge, 321-327.

Jensen, M.C., William H., \& Meckling. W.H. (1976). Theory of the Firm: Managerial Behavior, Agency Costs and Ownership Structure. Journal of Financial Economics,3(4), 305-360. http://dx.doi.org/10.1016/0304-405X(76)90026-X

Kaplan, R.S., \& Norton, D.P. (1996). Using the balanced scorecard as a strategic management system, Harvard Business Review, Retrieved 6 May, 2006 from: http:/downloanMicrosoft.com/download/6/1/C/61CB9EEB-EDA2-4D11ADED-47F653136094/balancedscorecard.pdf

Karels, G., \& Prakash, A. (1987). Multivariate normality and forecasting business bankruptcy, Journal of Business, Finance and Accounting, 14(4), 573 - 593.http://dx.doi.org/10.1111/j.1468-5957.1987.tb00113.x

Khandwalla, P.N., (1972). The effect of different types of competition on the use of management controls. Journal of Accounting Research.10(2), 275-285.

Koh, H. C., \& Killough, L. N. (1990). The Use of Discriminant Analysis in the Assessment of the Going Concern Status of an Audit Client, Journal of Business Finance and Accounting, 17(2), 179-192. http://dx.doi.org/10.1111/j.1468-5957.1990.tb00556.x

Muller, G.H., Steyn-Bruwer, B.W., \& Hamman, W.D. (2009). Predicting financial distress of companies listed on the JSE - A comparison of techniques, South African Journal of Business Management,40(1), 21-32.

Mutchler, J. F. (1985). A Multivariate Analysis of the Auditor's Going Concern Opinion Decision, Journal of Accounting research, 23(2). 668-682. http://dx.doi.org/10.2307/2490832

Ohlson, J. A. (1980). Financial Ratios and the probabilistic prediction of bankruptcy, Journal of Accounting Research, 18(1),109-131. http://dx.doi.org/10.2307/2490395

Pramodh, C., \& Ravi, V. (2007). Modified Great Deluge Algorithm based Auto Associative Neural Network for Bankruptcy Prediction in Banks. International Journal of Computational Intelligence Research. 3(4). 363370.http://dx.doi.org/10.5019/j.ijcir.2007.117

Shah, S.Z.A., Butt, S.A., \& Saeed, M.M. (2011). Ownership structure and performance of firms: Empirical evidence from an emerging market. African Journal of Business Management, 5(2), 515-523.

Sharma, M., \& Wadhawan, P. (2009). A Cluster Analysis Study of Small and Medium Enterprises. The IUP Journal of Management Research, 8(10), 7-23.

Seiford, L.M., \& Thrall, R.M. (1990). Recent Developments in DEA: The Mathematical Programming Approach to Frontier Analysis. Journal of Econometrics, 4, 7-38.

Sinkey, F. J. (1975). A multivariate statistical analysis of the characteristics of problem banks. Journal of Finance, 30(1), 21-36.

Taffler R. J. (1983). The assessment of company solvency and performance using a statistical model. Accounting and Business Research, 13(52), 295-307.

Watkins, A. L. (2003). A balanced perspective: Using non-financial measures to assess financial performance. Healthcare Financial Management, 57(11), 76-80.

Whitaker, R. B. (1999). The early stages of financial distress. Journal of Economics and Finance, 23(2), 123-132. http://dx.doi.org/10.1007/BF02745946

Zavgren, C. V. (1985). Assessing the vulnerability to failure of American industrial Firms: A logistic analysis, Journal of Business, Finance \& Accounting, 12(1), 19-45. http://dx.doi.org/10.1111/j.1468-5957.1985.tb00077.x

Zavgren, C. V., \& Friedman, G. E. (1988). Are bankruptcy prediction models worthwhile? An application in securities analysis. Management International Review, 28(1), 34-44. 